\title{
A Definitive Study of Aliphatic and Aromatic ß-ketosulfoxides: Promising Aromatic Chelates
}

\author{
Erwin Boschmann ${ }^{1, ~ *, ~ R a y m o n d ~ N e v i n ~ K e l l e r ² ~}$ \\ ${ }^{1}$ Department of Chemistry and Chemical Biology, Indiana University Purdue University Indianapolis, Indianapolis, Indiana, United States \\ ${ }^{2}$ Department of Chemistry, University of Colorado, Boulder, Colorado, United States
}

Email address:

Erv@iu.edu (E. Boschmann)

${ }^{*}$ Corresponding author

To cite this article:

Erwin Boschmann, Raymond Nevin Keller. A Definitive Study of Aliphatic and Aromatic B-ketosulfoxides: Promising Aromatic Chelates. Science Journal of Chemistry. Vol. 9, No. 1, 2021, pp. 1-8. doi: 10.11648/j.sjc.20210901.11

Received: December 15, 2020; Accepted: December 31, 2020; Published: January 15, 2021

\begin{abstract}
This paper begins with a detailed description of the conditions necessary for the formation of chelates in general, and B-ketosulfoxides in particular. While symmetric chelates such as 2,4-pentanedione have been known and studied for a long time, asymmetric chelate structures, such as the aliphatic $\omega$-(methylsulfinyl)-acetophenone, $\mathrm{Ph}-\mathrm{CO}-\mathrm{CH}_{2}-\mathrm{SO}-\mathrm{CH}_{3}$, for example, have not been investigated. Our detailed studies of solubility, acidity, IR, UV, and NMR spectroscopies all indicate very low enolization and hence low chelation, if any. Nevertheless, using rather strong conditions - such as molten reagents - we experienced some evidence for reaction. We extended our studies to aromatic ketosulfoxides by fusing these into benzene, assuming that its resonating ring will not only withdraw electrons from the $\mathrm{S}=\mathrm{O}$ group, but might also encourage conjugation. We focused on $\underline{0}$-(methylsulfoxo)-acetophenone with its $\mathrm{S}=\mathrm{O}$ group in one position on the benzene ring and the $-\mathrm{OH}$ group in an adjacent position. Three separate facts confirmed our belief that such a fused structure should undergo enolization and thus chelation. First, salicylaldehyde and 2-hydroxyacetophenone, both structurally analogous to the compound of interest $\underline{\mathbf{o}}-$ (methylsulfoxo)-acetophenone, do show strong chelation; second, approximate linear combination of atomic orbitals-molecular orbital (LCAO-MO) calculations point to positive results; and third, a comparison of the acidity constants of six acids ranging from $\omega$-(methylsulfinyl)-acetophenone $\left(3 \times 10^{-11}\right)$ to salicylic acid $\left(1.06 \times 10^{-3}\right)$ place the compound in question, $\underline{\mathbf{o}}-$ (methylsulfoxo)-acetophenone, at the upper end of acidity. Indeed, metal derivatives of $\underline{o}$-(methylsulfoxo)-acetophenone form rather easily as evidenced by $\mathrm{O}-\mathrm{H}$ and $\mathrm{S}=\mathrm{O}$ shifts in IR, $\mathrm{UV}$, and NMR spectroscopies. Calcium forms a chelate, whereas iron and niobium form adducts.
\end{abstract}

Keywords: Asymmetric Chelates, Aliphatic B-ketosulfoxides, Aromatic B-ketosulfoxides, Chelates, B-ketosulfoxides

\section{Introduction}

Chelates have fascinated chemists for a long time. While natural chelates such as hemoglobin, chlorophyll, or vitamin $\mathrm{B}-12$, exist in nature, as 'natural' implies, the chemical identification of these claw-like structures, and its name 'chelate', are more recent [1].

Good chelates fulfill the following conditions:

1. Symmetric structure.

2. Ability to form a stable ring structure.

3. Formation of a resonance structure of alternating single and double bonds.

4. Hydrogen bond formation with a neighboring electronegative point.

5. Formation of the acidic - $\mathrm{OH}$ group enolization, through the intra-molecular shift of a hydrogen atom onto an end atom (usually oxygen or nitrogen).

6. Negative charge delocalization into the chelating system. The higher the delocalization, the higher its chelating potential.

7. The $-\mathrm{OH}$ hydrogen replacement by an incoming atom, usually a metal. The strength of this bond is directly proportional to the acidity of the $-\mathrm{OH}$ group.

8. Chelation, the formation of a complex involving two or more separate coordinate bonds between a polydentate ligand and a single central atom or ion. 
2,4-Pentanedione, fulfills these requirements beautifully and forms many metal chelates,<smiles>CC(=O)C=C(C)C#N</smiles>

which have been the subject of a plethora of investigations. This fascination stems not only from the multitude of metal ions undergoing chelation, but in the case of transition metal ions, their versatility of $d$ electrons as potential pi bonders provides an even greater variety of colorful chemistry.

Thus, the extent of enolization through alternating single/double bonds, and the resulting acidity establishing chelating ability are primary factors in the formation of chelates. Enolization is the intramolecular shift of hydrogen onto an oxygen (or nitrogen) to form an $-\mathrm{OH}$ (or $>\mathrm{NH}$ ) group; chelation is the process by which a molecule (or ion) bonds through one or more coordinating sites to another atom (or ion).

In an effort to extend this chemistry to new potential chelates, we knew that, aside from maintaining the above mentioned conditions, other conditions must be fulfilled as well. Among these are, a) that there be evidence of bond formation of the ligand points to a metal ion; $b$ ) that there be no, or little steric hindrance; c) that the new ligand point not be a major resonance insulator; and d) that any lack of symmetry be overcome, at least in part, by other contributing pro-chelating attributes.

After consideration it was concluded that substituting one $\mathrm{C}=\mathrm{O}$ in 1 with an $\mathrm{S}=\mathrm{O}$ might warrant investigation:

$$
\begin{array}{cc}
\mathrm{O} & \mathrm{O} \\
\| & \| \\
\mathrm{R}-\mathrm{S}-\mathrm{CH}_{2}-\mathrm{C}-\mathrm{R}^{\prime} \\
\text { ß-ketosulfoxide }
\end{array}
$$

\section{Experimental Section}

\subsection{Selected Compound Preparations}

$\omega$-(methylsulfinyl)-acetophenone, $\mathrm{Ph}-\mathrm{CO}-\mathrm{CH}_{2}-\mathrm{SO}-\mathrm{CH}_{3}$, was prepared based on published procedures [2] but was modified through vacuum distillation for the removal of excess dimethyl sulfoxide, and refluxing for several hours taking care not to cause oxidation to the sulfone.

Twenty milliliters $(0.25$ moles $)$ of dimethyl sulfoxide were mixed with fifty milliliters tetrahydrofuran. One tenth mole (four grams) metallic potassium was added piece by piece and the resulting solution of dimethyl sulfoxide salt was stirred and chilled to about $0{ }^{\circ} \mathrm{C}$, whereupon a total of 0.05 mole ethylbenzoate was added dropwise under nitrogen atmosphere. As the reaction mixture was allowed to warm to room temperature, a yellow precipitate formed which dissolved upon addition of water and hydrochloric acid $(\mathrm{pH}$ 5-6) giving a lemon yellow solution. (A brown solution signals the undesirable oxidation to sulfone.) Addition of acid converted the ketosulfoxide and dimethyl sulfoxide anions to their respective acid forms, making the former soluble in organic solvents and the latter soluble in water. The product was isolated through extraction with five $100-\mathrm{mL}$ portions of chloroform. Since every extraction carried along some dimethyl sulfoxide, the chloroform had to be washed with five or six 50-mL portions of water, dried over magnesium sulfate, and then evaporated using a rotovac. The yellowbrown oil, when placed in contact with ether, was instantly converted to yellow needles. Several washings with small quantities of ether yielded a colorless compound melting at $84^{\circ} \mathrm{C}$ (Literature value $85^{\circ} \mathrm{C}$ ). Sulfur analysis of $17.60 \%$ was calculated for $\mathrm{C}_{9} \mathrm{H}_{10} \mathrm{SO}_{2}$ and found to be $17.56 \%$. Titration with $\mathrm{NaOH}$ showed a pK of 10.5 , and its reactivity toward metals decreased: $\mathrm{K}>\mathrm{Na}>\mathrm{Ca}>\mathrm{Mg}$. Another synthesis has been proposed by Posner [3].

o-(methylsulfoxo)-phenol, $\mathrm{C}_{7} \mathrm{H}_{8} \mathrm{SO}_{2}$, (HSox) also known as o-hydroxyphenyl methyl sulfoxide, was prepared from the commercially available 2-(methylmercapto)-phenol following published procedure [4]. It is easily oxidized to its sulfoxide yielding a product with a melting point of $128^{\circ} \mathrm{C}$ (Literature value $\left.128-9^{\circ} \mathrm{C}\right)$. The sulfur analysis calculated for $\mathrm{C}_{7} \mathrm{H}_{8} \mathrm{SO}_{2}$ is $20.53 \%$, and found to be $20.48 \%$. $\mathrm{pK}_{\mathrm{a}}$ value is 7.5 .

Sodium o-(Methylsulfoxo)-phenol was prepared by refluxing o-(methylsulfoxo)-phenol in chloroform over sodium hydride for some 24 hours. The salt has a dual melting point; at $152^{\circ} \mathrm{C}$ it became a liquid but solidified immediately changing from light red to deep brown above $200^{\circ} \mathrm{C}$. Sulfur analysis calculated for $\mathrm{NaC}_{7} \mathrm{H}_{7} \mathrm{SO}_{2}$ is $18.00 \%$; found $18.00 \%$.

Calcium o-(Methylsulfoxo)-phenol was prepared by mixing finely ground calcium hydride and the sulfoxide in chloroform, stirred and refluxed for some 24 hours. The appearance of hydrogen gas and the formation of a white precipitate suggesting a reaction in process. The precipitate was filtered, washed, dried, yielding about eighty percent product. Around $100^{\circ} \mathrm{C}$ a change in crystal rearrangement occurred, however, no further change took place up to $300^{\circ} \mathrm{C}$. No accurate sulfur analysis or titration could be obtained.

Its UV intensities in 95\% ethanol depend on both time and temperature. An immediate spectrum of freshly prepared compound, and repeated a various times thereafter (up to five days) shows an isosbestic point at $293 \mathrm{~m} \mu$ for the first order reaction $\mathrm{Ca}(\mathrm{Sox})_{2}+2 \mathrm{H}_{2} \mathrm{O} \leftrightarrow \rightarrow 2 \mathrm{HSox}+\mathrm{Ca}^{++}+2 \mathrm{OH}^{-}$. Using $A=\varepsilon b c$ [where $A$ is the absorbance, $\varepsilon$ the extinction coefficient, and $b$ the cell path] a plot of $\log A_{o} / A_{t} v s$. time gives a straight line with a slope of $3 \times 10^{-3}$, a $k$ value of $8 \times$ $10^{-3} \mathrm{hrs}^{-1}$ and a $t_{1 / 2}$ of about 90 hours.

Ferric Chloride-o-(Methylsulfoxo)-phenol. Threethousands of a mole $(0.468 \mathrm{~g})$ of the sulfoxide was placed in a pear-shaped flask, flushed with dry nitrogen, and the temperature raised slowly. At the melting point of the sulfoxide, $10^{-3}$ mole $(0.162 \mathrm{~g})$ of anhydrous ferric chloride was added and the temperature raised slowly, yet not allowed to get so high as to cause decomposition (evidenced by dense fumes). Recrystallization from acetone gave shiny, red crystals melting at $55^{\circ} \mathrm{C}$. Ignition resulted in an eighty-seven per cent loss by weight, which compares favorably to the 
theoretical loss yielding ferric oxide $\left(\mathrm{Fe}_{2} \mathrm{O}_{3}\right)$ of eighty-six per cent. Analysis by Galbraith Laboratories found C: 40.32\%; H: $3.80 \%$; $\mathrm{Fe}: \quad 8.68 \%$; S: $14.96 \%$. Calculated for $\mathrm{FeCl}_{3} .3\left(\mathrm{C}_{7} \mathrm{H}_{8} \mathrm{SO}_{2}\right) ; \mathrm{C}: 39.98 \%$; H: 3.83\%; Fe: $8.85 \%$; S: $15.25 \%$.

Niobium Pentachloride·o-(Methylsulfoxo)-phenol. This adduct formed upon mixing the reactants in the absence of air. The mixture was allowed to stand for several days in benzene, after which a yellow precipitate formed quantitatively. If isolated under nitrogen, the product had a melting point of $185^{\circ} \mathrm{C}$. If, however, air was admitted, it decomposed rapidly yielding $\mathrm{Nb}_{2} \mathrm{O}_{5}$, which does not melt below $300^{\circ} \mathrm{C}$. Ignition of freshly prepared material gave $69.11 \%$ loss, compared to the theoretical loss of $68.83 \%$.

\subsection{Instrumentation Used}

IR. Potassium bromide discs were prepared for each compound and run on either a Beckman IR-5 spectrophotometer for the two to sixteen micron region, or a Beckman IR-10 and/or a Perkin-Elmer Infracord. Polystyrene was used as a standard employing the $1601 \mathrm{~cm}^{-1}(6.24$ microns) and $698.9 \mathrm{~cm}^{-1}$ (14.31 micron) absorptions as standard reference peaks.

UV. Standard concentrated stock solutions were prepared by weighing the required amount of solid and dissolving in in U.S.I. absolute pure ethanol. This solution was then used for the preparation of subsequent, more dilute solutions. The chart speed on the Cary 14 spectrophotometer was set at 30 $\mathrm{m} \mu /$ inch, and reducing the speed to $15 \mathrm{~m} \mu / \mathrm{inch}$ when repeating a run for the purpose of absorption maxima assignment. Quarz cells of $10 \mathrm{~mm}, 1 \mathrm{~mm}$, and $0.1 \mathrm{~mm}$ were used.

NMR. All spectra were recorded on a Varian Associates 60 Analytical NMR Spectrometer at a frequency of 60 megacycles per second. Chemical shifts were observed in ppm $(\delta)$ relative to tetramethylsilane. Solvents used included benzene, ethanol, methanol, carbon disulfide, dimethyl sulfoxide, chloroform, deuteroform, deuterated water, and carbon tetrachloride.

Sulfur Analysis. The simple and accurate Wolfgang Schöniger method described by Walton [5] was used to obtain the sulfur content in the compounds prepared. Fifty to one hundred milligrams of the sample were wrapped in a small paper flag which was then placed into a platinum gauze clip attached to the stopper of a $500-\mathrm{mL}$ flask. A few milliliters of dilute hydrogen peroxide were introduced as absorbing solution. The flask was then flushed with oxygen, closed, and the sample ignited electrically. After the ignition was complete, the flask was shaken vigorously for several minutes to allow all sulfur dioxide to be absorbed into the solution, and boiled to remove excess peroxide. Enough isopropyl alcohol was added to make the solution $80 \%$ in this solvent, Thorin indicator added, and the solution titrated with $0.01 \mathrm{~N}$ barium perchlorate. This method gives an accuracy of $0.3 \%$.

Titration. Titration curves were obtained by dissolving $10^{-3}$ moles of acid in $50 \mathrm{~mL}$ distilled water and titrating at $25^{\circ} \mathrm{C}$ with standard sodium hydroxide. A Beckman Zeromatic $\mathrm{pH}$ Meter and Sargent $\mathrm{pH}$ Combination Electrode were used.

\section{Results and Discussion}

\subsection{Aliphatic Ketosulfoxides}

Some facts about aliphatic ketosulfoxides become immediately obvious:

1. The loss of symmetry and the possible resulting (at least partial) loss of a resonance structure;

2. The resulting absence of (major) enolization;

3. While the $\mathrm{C}=\mathrm{O}$ group is planar allowing easy access of a metal ion, the $\mathrm{S}=\mathrm{O}$ group is of the bulkier pyramidal structure;

4. The rather easy, sometimes uncontrolled oxidation of $\mathrm{S}=\mathrm{O}$ to $\mathrm{SO}_{2}$;

5. The -S- group has long been known to be a resonance insulator [6];

6. Sulfur has available $d$ orbitals which can result in an expansion of the octet causing an uneven distribution of electrons thereby, at least in part, hindering conjugation, and thus chelation;

7. The effective basicity of the $\mathrm{S}=\mathrm{O}$ oxygen toward hydrogen ions is lower than that of the $\mathrm{C}=\mathrm{O}$ oxygen, since much of the otherwise available electron cloud in sulfoxide is tied up in (d-p) $\pi$ bonding between sulfur and its oxygen.

There is, however, plenty evidence that single $\mathrm{S}=\mathrm{O}$ points, such as dimethyl sulfoxide, bond metals through oxygen, and in some cases, such as $\mathrm{Pt}(\mathrm{II}), \mathrm{Pd}(\mathrm{II}), \mathrm{Hg}(\mathrm{II})$, the bonding is through sulfur [7-9].

B-ketosulfoxides were first prepared in the early 1960 s [10]; and based on their structure they appear to possess chelate potential; even though the sulfoxide group is tetrahedral, a 'chelate bite' should be provided for.

However, the actual story is different. Solubility, acidity, spectral evidence, hydrogen bonding, and 'benzenoid' character (resonance within a chelate system) are all almost absent. Using $\omega$-(methylsulfinyl)-acetophenone, $\mathrm{Ph}-\mathrm{CO}-\mathrm{CH}_{2}-$ $\mathrm{SO}-\mathrm{CH}_{3}$, as an example of $\beta$-ketosulfoxides, let us consider some evidence for such sluggish chelation.

Solubility rules indicate that the less polar enol form, would be most soluble in non-polar solvents,

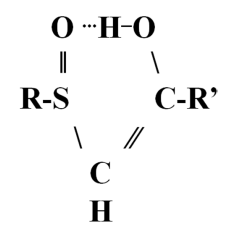

whereas the more polar keto form,

$$
\begin{array}{cc}
\mathrm{O} & \mathrm{O} \\
\| & \| \\
\mathrm{R}-\mathrm{S}-\mathrm{CH}_{2}-\mathrm{C}-\mathrm{R} &
\end{array}
$$

would be soluble in polar solvents. Diketones dissolve best in non-polar solvents, therefore the enol form predominates, 
whereas the opposite is true for B-ketosulfoxides - they dissolve only in polar solvents indicating that they exist primarily in the keto form.

Acidity considerations dictate that if chelation is to occur readily the enol hydrogen has to be acidic enough to replace incoming metal ions with relative ease. Titration, however, indicates a $\mathrm{K}_{\mathrm{a}}$ for $\omega$-(methylsulfinyl)-acetophenone of just 3 x $10^{-11}$ - making it virtually non-acidic, and two powers of ten lower than that of the diketone acetylacetone. (See Table 2) Furthermore, an attempt at bromination was unsuccessful indicating that no substantial amount of $\mathrm{C}=\mathrm{C}$ is present, or that acidity, if any, is provided by $=\mathrm{CH}$ -

Infrared studies also assist in pointing to evidence of chelation - or lack thereof. (See Figures 1 and 2). Hydrogen bonding and acidity go hand in hand, and both depend on negative charge delocalization. Extensive negative charge delocalization will provide for a good chelating agent. It is known that upon enolization $\mathrm{C}=\mathrm{O}$ bands are shifted downward since the bond is weakened due to hydrogen bonding and the loss of one of its bonds.

Diketonates, because of their symmetry and conjugation allow equal charge distribution over the entire chelate system, and all IR bands in the new ring will be affected.

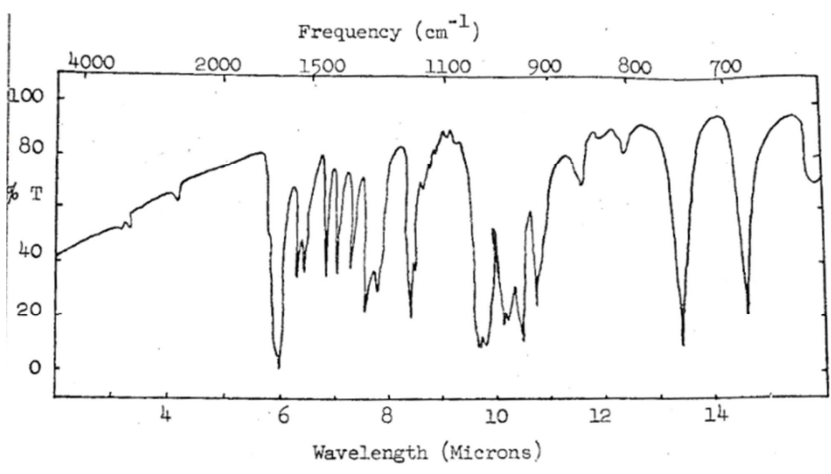

Figure 1. Infrared Spectrum of $\mathrm{Ph}-\mathrm{CO}-\mathrm{CH}_{2}-\mathrm{SO}-\mathrm{CH}_{3}$.

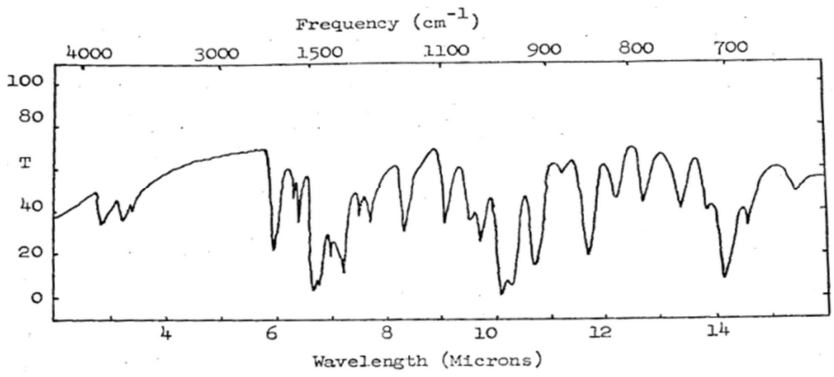

Figure 2. Infrared Spectrum of $\mathrm{Ph}-\mathrm{CO}-\mathrm{CH}=\mathrm{SO}-\mathrm{CH}_{3}{ }^{-} \mathrm{Na}^{+}$.

Table 1. Selected infrared absorptions of $\omega$-(methylsulfinyl)-acetophenone and some of its metal derivatives.

\begin{tabular}{lllll}
\hline \multirow{2}{*}{ Compound } & \multicolumn{2}{c}{ Absorptions in microns } & & \\
\cline { 2 - 5 } & O-H & $\mathbf{C}=\mathbf{O}=\mathbf{O}$ & M-O \\
\hline $\mathrm{PhCOCH}_{2} \mathrm{SOCH}_{3}$ & $3.3(\mathrm{vw})$ & 5.99 & 9.79 & - \\
$\mathrm{Na}^{+}\left[\mathrm{PhCOCHSOCH}_{3}{ }^{-}\right]$ & - & 5.98 & 9.76 & 9.55 \\
$\mathrm{~K}^{+}\left[\mathrm{PhCOCHSOCH}_{3}{ }^{-}\right]$ & - & 6.00 & $9.75,10.10$ \\
$\mathrm{Ca}^{++}\left[\mathrm{PhCOCHSOCH}_{3}{ }_{2}\right.$ & - & 5.99 & 14.10 \\
$\mathrm{FeCl}_{3} \cdot \mathrm{PhCOCH}_{2} \mathrm{SOCH}_{3}$ & $3(\mathrm{~b})$ & 5.99 & 10.00 \\
\hline
\end{tabular}

ß-ketosulfoxides lack both symmetric structure, and available $d$ orbitals which could accommodate extra electrons. Its octet expansion causes an uneven distribution of electrons which synergistically hinders conjugation, and thus chelation.

Preparing a salt of $\omega$-(methylsulfinyl)-acetophenone, (Figure 2 and Table 1) by forcing its reaction with an alkali, if enolization were to occur, the following spectral changes might be expected: the weakening of either the $\mathrm{C}=\mathrm{O}$ or $\mathrm{S}=\mathrm{O}$ bands, depending on where the alkali metal is attached; the corresponding appearance of the $\mathrm{C}-\mathrm{O}$ or $\mathrm{S}-\mathrm{O}$ bands, corresponding appearance of the $\mathrm{C}=\mathrm{C}$ or $\mathrm{C}=\mathrm{S}$; and the appearance of the M-O band.

In fact, the observations are that the reaction (which only goes at higher temperatures) the $\mathrm{C}=\mathrm{O}$ band is unchanged and the $\mathrm{S}=\mathrm{O}$ band is diminished very slightly; a weak $\mathrm{S}-\mathrm{O}$ band appears around $11.76 \mu\left(850 \mathrm{~cm}^{-1}\right), \mathrm{C}=\mathrm{S}$ bands at $9.09 \mu$ $\left(1100 \mathrm{~cm}^{-1}\right)$ and $9.345 \mu\left(1070 \mathrm{~cm}^{-1}\right)$, and a $\mathrm{M}-\mathrm{O}$ band appears around $14.08 \mu\left(710 \mathrm{~cm}^{-1}\right)$. The alkali metal bonds through the $\mathrm{S}=\mathrm{O}$ oxygen only, leaving the $\mathrm{C}=\mathrm{O}$ band unperturbed.

Based on infrared data for $\mathrm{Ph}-\mathrm{CO}-\mathrm{CH}_{2}-\mathrm{SO}-\mathrm{CH}_{3}$, we conclude that

1. The ketosulfoxide is not an acid;
2. There is small evidence for the formation of $-\mathrm{OH}$;

3. When a salt forms it is via $-\mathrm{CH}_{2}-$;

4. The -SO- peak appears in the same place as that for any R-SO-R';

5. Enolization is very low; and when forced, it occurs through the sulfoxide group.

UV theory predicts that a given $\mathrm{S}=\mathrm{O}$ peak will be shifted to longer wavelength (lower energy), to somewhere around $290 \mathrm{~m} \mu$, when conjugation takes place. Simple sulfoxides, on the other hand, absorb at less than $270 \mathrm{m \mu}$ [11] (Figure 3) and show a strong peak at $248 \mathrm{~m} \mu$ for $\mathrm{Ph}-\mathrm{CO}-\mathrm{CH}_{2}-\mathrm{SO}-\mathrm{CH}_{3}$, thus indicating the absence of conjugation.

NMR spectroscopy also provides strong evidence for lack of enolization in aliphatic ketosulfoxides (Figure 4). An unperturbed hydroxyl hydrogen is known to resonate in the region between four and seven ppm $(\delta)$, whereas a hydrogen bonded hydroxyl hydrogen will resonate at a much lower field [12]. Furthermore, while for diketones there is evidence of a broad peak in this region indicating hydrogen bonding, and the ratio of $=\mathrm{CH}-:-\mathrm{CH}_{3}$ hydrogen absorption peaks is clearly $1: 3$, ketosulfoxide (same figure) shows a ratio of $\mathrm{CH}_{2}-: \mathrm{CH}_{3}$ of $2: 3$ and the position of the doublet is well outside the region for vinylic hydrogens. Again, there is little 
evidence for enolization.

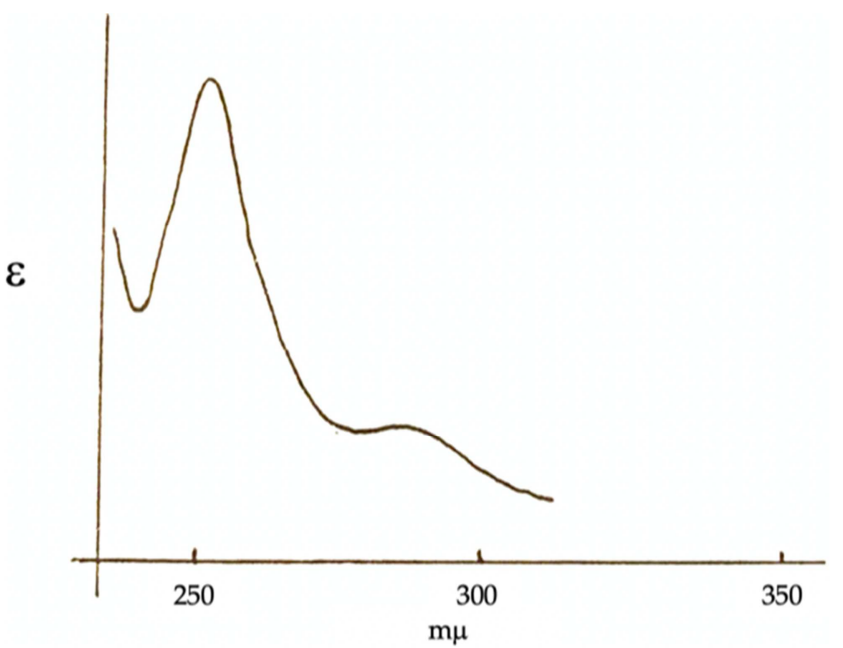

Figure 3. Ultraviolet Spectrum of $\mathrm{Ph}-\mathrm{CO}-\mathrm{CH}_{2}-\mathrm{SO}-\mathrm{CH}_{3}$ in Absolute Ethanol. Concentration: $3.88 \times 10^{-4} \mathrm{M}$; Cell path: $0.1 \mathrm{~cm}$.
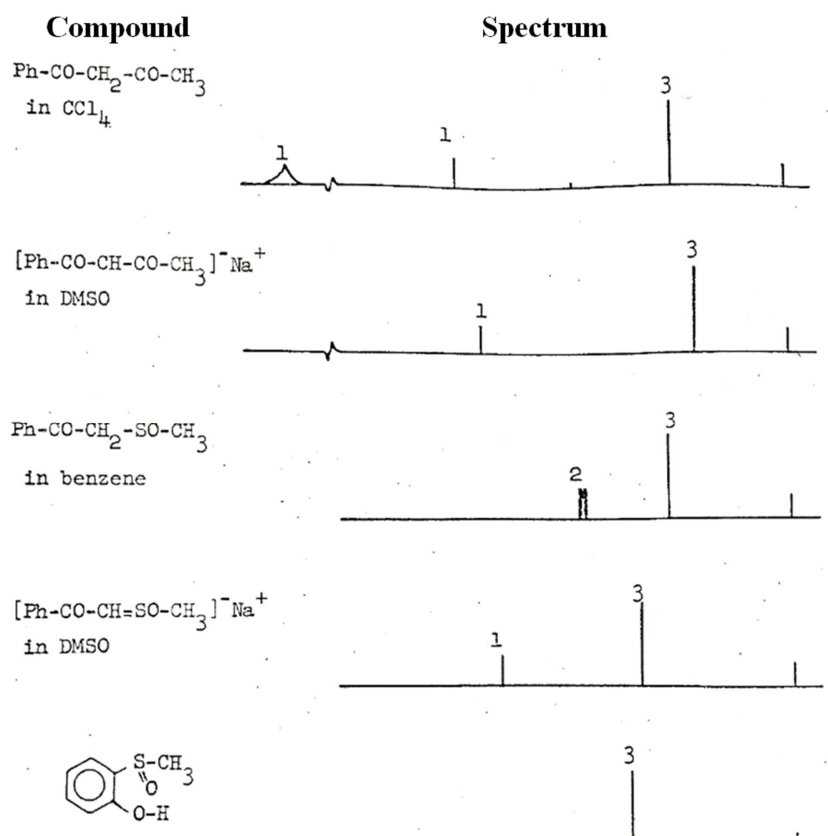

in $\mathrm{CDCl}_{3}$

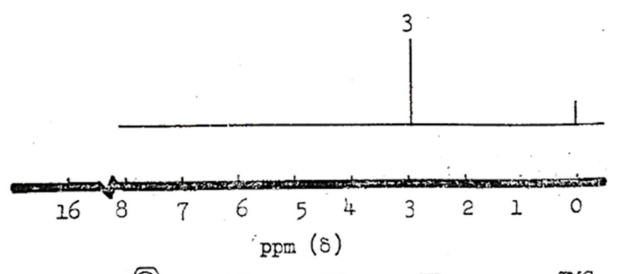

Type of

O...H-O

ppm (8)

Figure 4. Nuclear Magnetic Resonance Spectra of Diketo and Ketosulfoxo Compounds.

Still, using aqueous and non-aqueous environments and rather strong conditions such as molten reagents, we do have some evidence for reaction. We allowed eighteen metal salts to come into contact with our sulfoxide, and found sodium, potassium, calcium, $\mathrm{Hg}(\mathrm{II}), \mathrm{Cu}(\mathrm{II}), \mathrm{Sb}(\mathrm{III}), \mathrm{Pb}(\mathrm{II}), \mathrm{Pt}(\mathrm{II})$, $\mathrm{Pd}(\mathrm{II})$ and $\mathrm{Fe}(\mathrm{III})$ to show some slight evidence of reaction. However, through the year 2020 the literature is silent on any evidence of chelation, or even enolization, in aliphatic Bketosulfoxides.

\subsection{Aromatic Ketosulfoxides}

Since the absence of resonance in aliphatic $\beta-$ ketosulfoxides is a key reason for the absence of enolization (and thus chelation), it is postulated that a neighboring, already existing resonance system might assist in establishing resonance in $\beta$-ketosulfoxides. Fusion of a chelate structure into a resonating ring will not only withdraw electrons from the $\mathrm{S}=\mathrm{O}$ group, but might also encourage conjugation. An approximate LCAO-MO calculation points to the possibility of chelate formation in such systems.

An obvious example is o-(methylsulfoxo)-phenol:<smiles>CS(=O)c1ccccc1O</smiles>

here abbreviated as HSox, whose resonating benzene ring might assist in establishing resonance in the attached Bketosulfoxide system as well. Hydrogen bonding in HSox has been established and chelation has been inferred. [13]

By analogy, 2-hydroxyacetophenone<smiles>CC(=O)c1ccccc1O</smiles>

salicylaldehyde,<smiles>O=Cc1ccccc1O</smiles>
also known as ohydroxybenzaldehyde, or salicylic aldehyde, do have chelating properties [14], though these are reduced due to steric factors and the fact that resonance resides primarily in the benzene ring.

Comparing acidity constants is helpful (Table 2).

Table 2. Acidity constants for some acids.

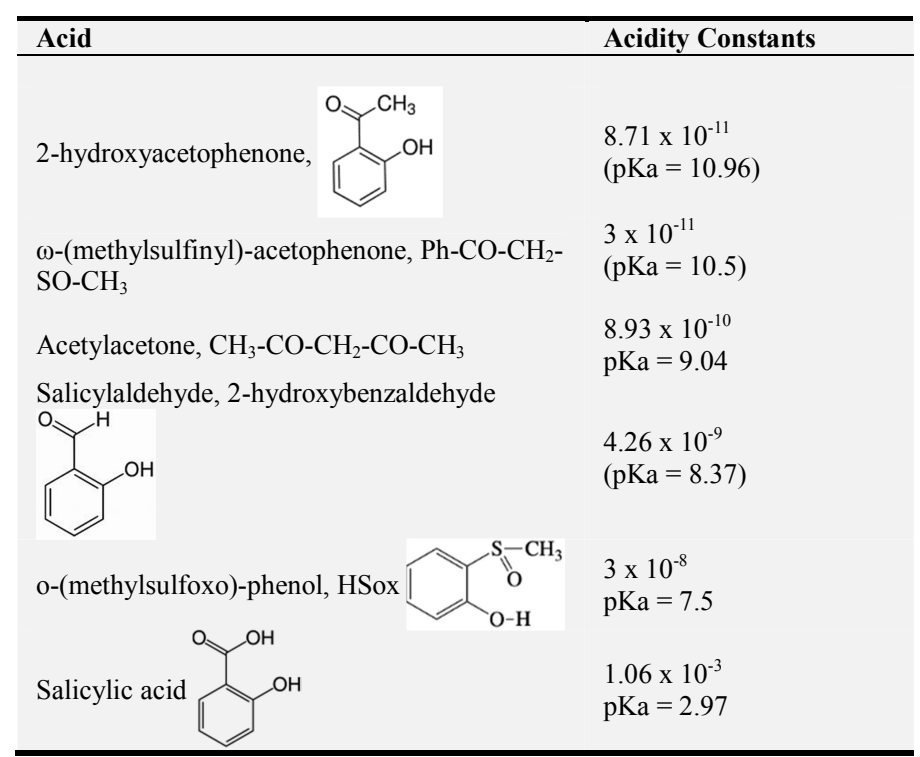

From this table it is evident that the acidity of HSox is very much stronger than that of $\mathrm{Ph}-\mathrm{CO}-\mathrm{CH}_{2}-\mathrm{SO}-\mathrm{CH}_{3}$, and stronger by several factors of ten even than acetylacetone, hence our expectation is that chelation should occur.

IR studies (Figure 5) show that the $\mathrm{O}-\mathrm{H}$ absorption band in 
o-(methylsulfoxo)-phenol, HSox, of its regular three micron region to longer wavelengths. Such shifts have been attributed to hydrogen bonding [15], $\mathrm{O} \ldots \mathrm{H}-\mathrm{O}$, where the $\mathrm{O}-\mathrm{H}$ bond is weakened resulting in a lowered vibrational O-H frequency. A similar observation is made in studies of the sulfoxide absorption band. Hydrogen bonding of the type H...O-S has the effect of weakening the $\mathrm{S}=\mathrm{O}$ bond strength thereby shifting the sulfoxide absorption to lower frequency (longer wavelength). The $-\mathrm{OH}$...OSbond distance has been found to be just $1.6926 \AA$ - one of the shortest of seventy four 2-substiuted phenols studied [16].

Simple sulfoxides show an IR absorption band around 9.5 $\mu\left(1052.6 \mathrm{~cm}^{-1}\right)$, whereas in o-(methylsulfoxo)-phenol, HSox, in accordance with theory, the sulfoxide stretching band is found at $10.10 \mu\left(990.1 \mathrm{~cm}^{-1}\right)$.

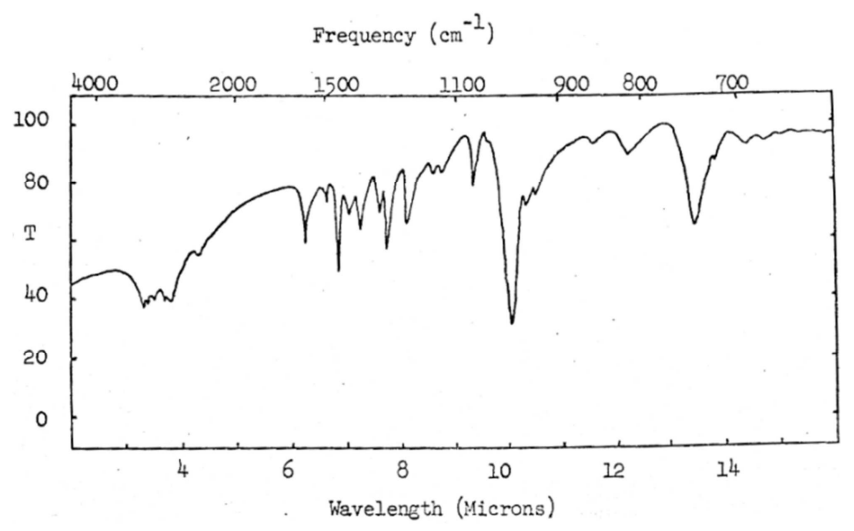

Figure 5. Infrared Spectrum of o-(Methylsulfoxo)-phenol, HSox.

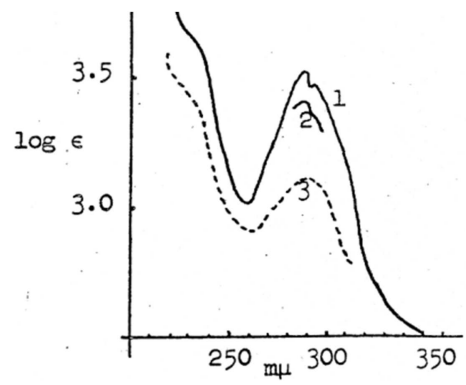

Figure 6. Ultraviolet Spectrum of o-(Methylsulfoxo)-phenol, HSox (1. In absolute alcohol; 2. In 95\% ethanol; 3. In water).

UV theory predicts that a given peak will be shifted bathochromatically (to longer wavelength; lower energy) when conjugation takes place. Thus, o-(methylsulfoxo)phenol, HSox, absorbs around $280 \mathrm{~m} \mu$ (Figure 6), a long wavelength compared to simple sulfoxides which absorb at less than $270 \mathrm{~m} \mu$ [11], giving evidence that a conjugated system has been established through hydrogen bonding. Recall the earlier discussion of $\mathrm{Ph}-\mathrm{CO}-\mathrm{CH}_{2}-\mathrm{SO}-\mathrm{CH}_{3}$ showing its absorption at $248 \mathrm{~m} \mu$ (Figure 3 ) indicating the absence of conjugation.

NMR spectra also give strong evidence for hydrogen bonding in o-(methylsulfoxo)-phenol (Figure 4). As stated earlier, unperturbed hydroxyl hydrogen is known to resonate in the region between four and seven ppm $(\delta)$, whereas hydrogen bonded hydroxyl hydrogen will resonate at much lower field [12]. The proton spectrum shows a peak due to the $-\mathrm{CH}_{3}$ group hydrogens at $2.9 \mathrm{ppm}(\delta)$. The absence of a peak between seven and four ppm $(\delta)$ is thus indicative that the $-\mathrm{OH}$ hydrogen is strongly hydrogen bonded.

However, the real test is chelation with metals.

Enolization in HSox need not be considered since the hydroxyl form is the only stable structure. What is of interest, however, is the extent of its acid character and hydrogen bonding, properties which would assure a good 'chelate bite,' and thus chelation. Figure 7 proves that HSox is a rather strong acid, in fact, about one and a half powers of ten stronger than acetylacetone $\left(3 \times 10^{-8}\right.$ vs. $\left.9 \times 10^{-10}\right)$. Chelation, if based on this result, should be extensive. (See Ref 13) However, as discussed earlier, a good 'benzenoid' arrangement may be hindered by the presence of resonance insulating sulfur.

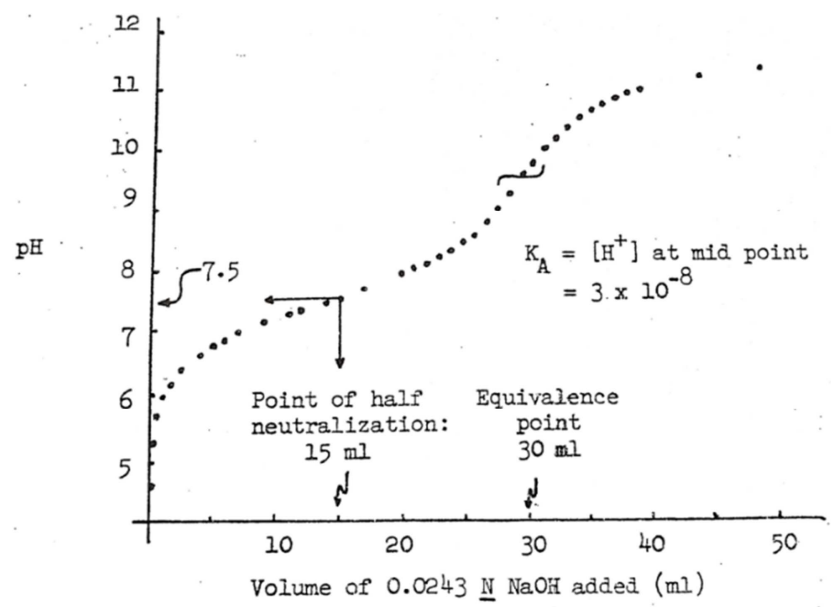

Figure 7. Titration of $0.0243 \mathrm{~N} \mathrm{NaOH} \mathrm{o-(methylsulfoxo)-phenol,} \mathrm{HSox,} \mathrm{in}$ Aqueous Solution.

We found that metal derivatives of HSox form rather easily. As expected, when a metal takes the place of the hydroxyl hydrogen, the IR broad three-micron band due to hydrogen bonded O-H absorptions disappears (Table 3) and Figure 5). Furthermore, the $10.10 \mu\left(990.1 \mathrm{~cm}^{-1}\right) \mathrm{S}=\mathrm{O}$ absorption band for HSox moved to $9.79 \mu\left(1021.45 \mathrm{~cm}^{-1}\right)$ and $9.88 \mu(1012.1$ $\mathrm{cm}^{-1}$ ) for the corresponding sodium and calcium derivatives, respectively. Of course, removal of the $-\mathrm{OH}$ hydrogen eliminates hydrogen bonding.

Table 3. Selected infrared absorptions of o-hydroxyphenyl methyl sulfoxide and some of its metal derivatives.

\begin{tabular}{lll}
\hline \multirow{2}{*}{ Compound } & \multicolumn{2}{l}{ Absorptions in microns } \\
\cline { 2 - 3 } & $\mathbf{O}-\mathbf{H}$ & $\mathbf{S}=\mathbf{O}$ \\
\hline $\mathrm{HSox}$ & $5.5(\mathrm{~b})$ & 10.10 \\
$\mathrm{Na}^{+}$salt & - & 9.79 \\
$\mathrm{Ca}^{++}$chelate & - & 9.88 \\
$\mathrm{FeCl}_{3}$ adduct & $2.95(\mathrm{~b})$ & 10.70 \\
$\mathrm{NbCl}_{5}$ adduct & $2.95(\mathrm{~b})$ & 10.73 \\
\hline
\end{tabular}

(b) = broad band

The $\mathrm{S}=\mathrm{O}$ has at least some double bond character which results from synergistic oxygen to sulfur $\mathrm{p} \pi \rightarrow \mathrm{d} \pi$ bonding and sulfur to oxygen sigma bonding. Attachment of oxygen 
to a positive atom will drain electrons from oxygen and lessen the extent of $\mathrm{p} \pi \rightarrow \mathrm{d} \pi$ back bonding [7]. Consequently, the $\mathrm{S}=\mathrm{O}$ bond order will be decreased and its stretching frequency lowered.

The sodium salt, Sox $\mathrm{Na}^{+}$, is found to have the smallest effect on the $\mathrm{S}=\mathrm{O}$ stretching frequency $\left(9.79 \mu ; 1021.45 \mathrm{~cm}^{-}\right.$ $\left.{ }^{1}\right)$. The calcium bonding is more pronounced and we propose its chelate structure to be<smiles>CS(=O)c1ccccc1O[C@H]1Oc2ccccc2[SH]1(C)=O</smiles>

with its sulfoxide $\mathrm{S}=\mathrm{O}$ absorption peak at $9.88 \mu$ (1012.15 $\left.\mathrm{cm}^{-1}\right)$ - about one tenth of a micron toward longer wavelength (lower frequency). Such partial drainage of electrons has lessened the $\mathrm{p} \pi \rightarrow \mathrm{d} \pi$ back bonding hence lowering the $\mathrm{S}=\mathrm{O}$ bond order, and the $\mathrm{S}=\mathrm{O}$ stretching frequency.

Other metal derivatives have been reported [17] showing that lithium and zinc form chelates with $\beta$-ketosulfoxides. Most metals, when bonded through the sulfoxide oxygen, will shift the sulfoxide frequency to lower values due to a drain of electrons from the S-O into the new O-M bond. However, for $\mathrm{Pt}(\mathrm{II}), \mathrm{Pd}(\mathrm{II})$ and $\mathrm{Hg}(\mathrm{II})$ these metals are all bound through the sulfur: M-S-O. Since electrons move from the oxygen environment into the S-O bond the SO frequency is shifted above the values of the sulfoxide. Ruthenium(II) [18] and iridium(III) [19] are chelated through sulfur as well.

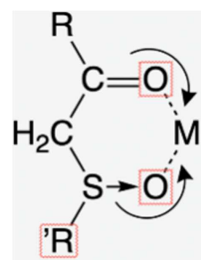

Ferric chloride and niobium pentachloride are different in that they apparently form adducts which show considerable shift of the $\mathrm{S}=\mathrm{O}$ absorption band to the $10.70 \mu\left(934.58 \mathrm{~cm}^{-1}\right)$ region (Table 3 ). Both adducts show strong $\mathrm{O}-\mathrm{H}$ absorption peaks indicating that no hydrogen has been replaced. It is reasonable to assume that these molecules have taken up a position around the sulfoxide oxygen and are thus preventing any hydrogen bonding. A supporting evidence that $\mathrm{FeCl}_{3} \cdot 3 \mathrm{HSox}$ and $\mathrm{NbCl}_{5} \cdot \mathrm{HSox}$ are simple adducts - not chelates - is the fact that the $\mathrm{O}-\mathrm{H}$ stretching frequency are virtually the same as that for the hydroxyl group in the ferric chloride adduct of $\mathrm{p}-\mathrm{HO}-\mathrm{C}_{6} \mathrm{H}_{4}-\mathrm{SO}-\mathrm{CH}_{3}$. If the hydroxyl groups in the HSox adducts were to participate in any kind of bonding, its absorption frequency would certainly be different from that of the hydroxyl group in the $\mathrm{FeCl}_{3} \cdot \mathrm{p}-\mathrm{HO}$ $\mathrm{C}_{6} \mathrm{H}_{4}-\mathrm{SO}-\mathrm{CH}_{3}$ adduct, where the hydroxyl group could not possibly participate in metal-to-ion bonding.

\section{Summary and Conclusion}

Chemical and instrumental studies have proven that aliphatic $\beta$-ketosulfoxides, though similar to $\beta$-diketones, possess no enolization or chelating properties. Such properties can be attained, however, by fusing a $\beta$ ketosulfoxide system with a resonating benzene ring. We found that o-(methylsulfoxo)-phenol shows both enolization and chelation with metals. Thus, sodium forms but a simple salt, whereas calcium shows chelate behavior, and both iron and niobium form adducts. These observations were confirmed via IR, UV, and NMR studies.

\section{Conflicts of Interest}

The authors declare that they have no competing interest.

\section{Acknowledgements}

We express our appreciation to Professor John S. Meek, University of Colorado, Department of Chemistry, who originally suggested this investigation. Professor Keller and I worked on this paper for several years exchanging notes and revisions. Unfortunately, Dr. Keller passed away prematurely and I put the draft aside. It has now been reworked and updated. Special thanks also go to Dr. Sara Dillie who reworked graphs, and to Eric A. Snajdr, science librarian, who spent time reviewing the $\beta$-ketosulfoxide literature for the recent decades to make sure that, to the best of our knowledge, no relevant work is missed. Finally, this work was abstracted in part, and findings were presented and published as preliminary results. [20]

\section{References}

[1] T. Morgan Gilbert, H. D. K. Drew, J. Chem. Soc. 117 (1920) 1456.

[2] E. J. Corey, M. Chaykovsky, J. Am. Chem. Soc., 86 (1964) 1639.

[3] G. H. Posner, in The Chemistry of Sulphones and Sulphoxides; S. Patai, Z. Rappoport, C. J. M. Stirling, Eds,; Wiley: New York, 1988, chapter 16, pages 824-849.

[4] K. Griesbaum, A. A. Oswald, B. E. Hudson, Jr., J. Am. Chem. Soc. 85 (1963) 1972.

[5] H. F. Walton, Principles and Methods of Chemical Analysis, $2^{\text {nd }}$ ed. Prentice-Hall, Inc., Englewood Cliffs, 1964, pages 176 and 383.

[6] E. A. Fehnel, M. Carmack, J. Am. Chem. Soc. 71 (1949) 84, $231,2889$.

[7] F. A. Cotton, R. Francis, J. Am. Chem. Soc. 82 (1960) 2986.

[8] F. A. Cotton, R. Francis, W. D. Horrocks, Jr. J. Phys. Chem. 64 (1960) 1534.

[9] F. A. Cotton, G. Wilkinson, Advanced Inorganic Chemistry, Interscience Publishers, New York, $2^{\text {nd }}$ edition, 1966, p. 1026; $3^{\text {rd }}$ edition, 1972, page 995 . 
[10] E. J. Corey, M. Chaykovsky, J. Am. Chem. Soc. 84 (1962) 866.

[11] H. H. Jaffe, M. Orchin, Theory and Application of Ultraviolet Spectroscopy, John Wiley and Sons, New York, 1962, page 491.

[12] J. R. Dyer, Applications of Absorption Spectroscopy of Organic Compounds, Prentice-Hall, Englewood Cliffs, (1965), pages 11,89 .

[13] A. O. Pedersen, G. Schroll, S. O. Lawesson, Tetrahedron 26 (1970) 4449-4471.

[14] S. A. Abdel-Latif, H. B. Hassib, Y. M. Issa, Spectrochimica Acta Part A: Molecular and Biomolecular Spectroscopy Volume 67, Issues 3-4, July (2007), Pages 950-957.

[15] L. J. Bellamy, The Infrared Spectra of Complex Molecules, Methuen and Co.., Ltd., London, 1958, chapters 9 and 22.

[16] H. G. Korth, M. I. de Heer, P. Mulder, J. Phys. Chem. A, 106 (2002) 8779-8789.
[17] M. C. Carreño, J. L. G. Ruano, A. M. Martin, C. Pedregal, J. H. Rodriguez, A. Rubio, J. Snachez, G. Solladie J. Org. Chem. 55 (1990) 2120-2128.

[18] Zheng-Zheng Li, A-Hao Wen, Su-Yang Yao, Bao-Hui Ye, Inorg. Chem. 54 (2015), 2726-2733.

[19] Su-Yang Yao, Xing-Yang Chen, Yan-Ling Ou, Bao-Hui Ye, Inorg. Chem. 56 (2017) 878-885.

[20] Abstracted in part from a thesis submitted by Erwin Boschmann to the Graduate School of the University of Colorado in partial fulfillment for the degree of Doctor of Philosophy, Department of Chemistry, 1968; and Presented in part before the $3^{\text {rd }}$ Central Regional American Chemical Society Meeting, June 6-8, 1971, Cincinnati, Ohio. A few preliminary results were published in R. N. Keller and Erwin Boschmann, Bol. Soc. Quim. 1968, 34, 107; and Erwin Boschmann, J. Inorg. Nucl. Chem. 1973, 35, 1025 (1973). 